\title{
O SIGNIFICADO DE SER PORTADOR DE TRANSTORNO MENTAL: CONTRIBUIÇÕES DO TEATRO ESPONTÂNEO DO COTIDIANO ${ }^{1}$
}

\author{
Francine Baltazar Assad ${ }^{2}$; \\ Luiz Jorge Pedrão ${ }^{3}$
}

\begin{abstract}
$\mathrm{Na}$ assistência aos portadores de transtornos mentais, o teatro espontâneo do cotidiano se apresenta como uma grande ferramenta. Este estudo objetivou compreender o que significa, para o portador de transtorno mental, de ser portador desse distúrbio. Para isso, quatro portadores de transtornos mentais participaram de quatro encontros, onde dramatizaram cenas de seu cotidiano, registradas através de fotografias, entrevistas e depoimentos, categorizadas por temas relativos à família, preconceito, medo e causa de ser um portador de transtorno mental, cuja análise permitiu considerar que o teatro espontâneo do cotidiano constituiu-se em uma ferramenta importante, possibilitando ressignificações e contribuição na reabilitação psicossocial.
\end{abstract}

Descritores: Transtornos Mentais; Saúde Mental; Reabilitação; Terapia Ocupacional.

\footnotetext{
${ }^{1}$ Apoio financeiro da Fundação de Amparo à Pesquisa do Estado de São Paulo (FAPESP), processo no 2008/56477-1.

2 Terapeuta Ocupacional, Doutoranda em Enfermagem, Escola de Enfermagem de Ribeirão Preto, Universidade de São Paulo, Centro Colaborador da OMS para o Desenvolvimento da Pesquisa em Enfermagem, SP, Brasil. E-mail: franassad@hotmail.com.

${ }^{3}$ Enfermeiro, Doutor em Enfermagem, Professor Doutor, Escola de Enfermagem de Ribeirão Preto, Universidade de São Paulo, Centro Colaborador da OMS para o Desenvolvimento da Pesquisa em Enfermagem, SP, Brasil. E-mail: lujope@eerp.usp.br.
} 


\section{THE MEANING OF HAVING A MENTAL DISORDER: CONTRIBUTIONS FROM EVERYDAY SPONTANEOUS THEATER}

Everyday spontaneous theater is a great tool in care delivery to patients with mental disorders. This study aimed to understand the meaning of being a mental disorder patient for people with this disorder. Therefore, four mental disorder patients participated in four meetings, where they dramatized scenes of their own daily life, registered through photographs, interviews and statements, categorized in themes related to family, prejudice, fear and cause of being a mental disorder patient. Analysis of the material permitted considering everyday spontaneous theater as an important tool, which permits re-significations and contributes in psychosocial rehabilitation.

Descriptors: Mental Disorders; Mental Health; Rehabilitation; Occupational Therapy.

\section{El SIGNIFICADO DE SER PORTADOR DE TRASTORNO MENTAL: CONTRIBUCIONES DEL TEATRO ESPONTÁNEO DEL COTIDIANO}

El teatro espontáneo del cotidiano es una buena herramienta en la atención a los pacientes con trastornos mentales. Este estudio tuvo como objetivo comprender el significado, para el portador de trastorno mental, de ser portador de trastorno mental. Cuatro pacientes con trastornos mentales participaron de cuatro encuentros, donde dramatizaron escenas de su cotidiano, registradas a través de fotografías, entrevistas y declaraciones, categorizadas en temas relativos a la familia, prejuicio, miedo y causa de ser portador de trastorno mental, cuya análisis permitió considerar que el teatro espontáneo del cotidiano es una importante herramienta, posibilitando re-significaciones y contribución en la rehabilitación psicosocial.

Descriptores: Trastornos Mentales; Salud Mental; Rehabilitación; Terapia Ocupacional.

\section{Introdução}

Ao adotar o conceito de que a terapia ocupacional toma como problemática de partida a exclusão social, e tem como objetivo final a inclusão social ${ }^{(1)}$, optou-se por relatar, pesquisar e discutir o cotidiano de portadores de transtorno mental e sua assistência, com o objetivo de compreender, através da técnica teatro espontâneo do cotidiano, o significado de ser um portador de transtorno mental, e oferecer um instrumento para ressignificações, contribuindo para a reabilitação psicossocial de sujeitos acometidos por esse transtorno .

Nos séculos XVII e XVIII, ao louco, era reservado o espaço institucional da exclusão; não havia, ainda, uma relação com a doença, e sim uma reação da sociedade, em reconhecer ou não a conduta dos indivíduos. O louco era visto como um animal, desprovido de sua racionalidade; a loucura passa a ser sinal de humilhação e sofrimento, levando os pacientes a serem confinados num espaço isolado do convívio social ${ }^{(2-3)}$. A partir do momento em que se passou a entender o louco como alguém que representava riscos e periculosidade social, foram inauguradas a institucionalização da loucura pela medicina e a ordenação do espaço hospitalar ${ }^{(4)}$.

No final do século XVIII, começo do século XIX, surge como primeira modalidade de intervenção terapêutica $\mathrm{o}$ tratamento moral, estabelecido por Pinel e, posteriormente, desenvolvido por Meyer ${ }^{(5)}$. Nesse momento, é notável perceber uma primeira tentativa de se utilizar o "fazer" como estratégia terapêutica e, possivelmente, o início da 
trajetória da prática da terapia ocupacional na assistência ao portador de transtorno mental.

Embora fossem estratégias terapêuticas, porém, historicamente, são identificados fatores que apontam para as instituições psiquiátricas como espaços em crise e que não cumpriam sua missão de tratamento e cura. Foi após o período de guerra, que a saúde foi assumida como direito, e algumas propostas foram reformuladas na assistência ao portador de transtorno mental, surgindo o início da reforma psiquiátrica ${ }^{(5)}$.

A efetivação da reforma requer a invenção de um novo lugar social para a experiência da loucura ${ }^{(6)}$. Isso implica a prática da reabilitação psicossocial, que seria um processo facilitador, por meio do qual o indivíduo passa a atingir o melhor nível possível de autonomia e exercício da cidadania $^{(7)}$.

Nessa perspectiva, pode-se destacar a terapia ocupacional. A desinstitucionalização italiana possibilitou inovações para a terapia ocupacional no campo da reforma psiquiátrica, ao assumir, como objeto da ação terapêutica, a pessoa e suas necessidades e não a doença e os sintomas. Nesse contexto, a ação terapêutica passa a investir na complexidade da vida cotidiana da pessoa, englobando os aspectos: práticos, concretos, simbólicos, relacionais e materiais, de forma a produzir movimentos capazes de oferecer suportes, proteção e resolução de problemas que contribuam para a superação da situação existencial ${ }^{(5)}$.

Ao pensar no contexto em que vivem portadores de transtornos mentais na atualidade, e em algumas estratégias e concepções que constituíram o pensamento psiquiátrico e suas práticas terapêuticas, o teatro espontâneo do cotidiano apresenta-se como importante instrumento da terapia ocupacional. As atividades expressivas visam a compreensão do sujeito, priorizando as potencialidades desse como um todo, a partir de vivências que contribuem para que o indivíduo se perceba e identifique diferentes "modos de funcionamento" em sua vida cotidiana ${ }^{(8)}$. O fazer artístico possibilita a "criação sobre o mundo real", o qual oferece ao sujeito um espaço para experimentar vivências criativas, proporcionando transformação de si, do cotidiano e das relações interpessoais ${ }^{(9)}$. As atividades expressivas sugerem o desenvolvimento de um processo criativo, o qual busca promover o contato entre os aspectos subjetivos e objetivos da realidade do indivíduo, abrindose espaço para o aparecimento de formas de expressão mais integradoras da sua personalidade ${ }^{(10)}$.

Baseado em Augusto Boal e Jacob Levi Moreno, o teatro espontâneo do cotidiano foi desenvolvido pela terapeuta ocupacional Márcia Pontes Mendonça, a qual relata que a improvisação é fundamental, pois possibilita culminar em ideias e temas, sem um texto elaborado previamente. $\mathrm{Na}$ improvisação, as falas e cenas são as cotidianas de cada sujeito, não havendo necessidade de um palco teatral, porém, um palco espaço que propicia um espaço da vida ${ }^{(11)}$.

O teatro espontâneo do cotidiano, que implica a utilização do jogo dramático, tem se mostrado importante canal de expressão, por meio do qual o sujeito vivencia situações e papéis de maneira descompromissada com as convenções e regras que direcionam o convívio social. Permite demonstrar os costumes das pessoas, recriar histórias e situações do seu cotidiano, suas necessidades, suas limitações, seus medos, sua opressão, e proporciona o desenvolvimento de habilidades em recriar suas ações, no sentidodaresoluçãodeconflitos, permitindosuaparticipação social $^{(11)}$. Tem sido utilizado como instrumento terapêutico para que o indivíduo possa canalizar e expressar emoções, propiciando construção criativa em busca de soluções para problemáticas que surgem a partir de questões da vida cotidiana de cada um, podendo, dessa forma, ser utilizado para o desenvolvimento da comunicação, conscientização, imaginação e criatividade ${ }^{(12)}$.

\section{Método}

Trata-se de estudo transversal, de caráter qualitativo, e apresenta como pressupostos teóricos o modelo da Reabilitação Psicossocial ${ }^{(4,7,13)}$ e a abordagem do Interacionismo Simbólico ${ }^{(14)}$, constituindo, assim, a base teórica para a análise e discussão dos resultados. Os resultados serão aqui apresentados de forma descritiva, a partir dos dados coletados tanto nas entrevistas e nos registros do diário de campo, elaborado durante a atividade do teatro espontâneo do cotidiano, como nas transcrições das fitas e registros das discussões em grupo. Para a análise dos dados optou-se pela análise de conteúdo ${ }^{(15)}$.

Foram realizadas entrevistas, uma inicial, individual, partindo da seguinte questão norteadora: o que significa para você ser um portador de transtorno mental? Outra entrevista foi feita ao término da pesquisa, também de forma individual, com as seguintes questões norteadoras: após cada encenação, houve alguma mudança em relação ao que sentia ou pensava sobre o tema encenado? Qual? De maneira geral, houve alguma mudança no seu dia a dia depois de participar do grupo? Qual?

O grupo foi dividido em etapas, compostas por: $1^{\text {a }}$ etapa - uma conversa inicial, na qual foi lançada a questão norteadora "O que significa para você ser um portador de transtorno mental?", e estabelecido o tema; $2^{\text {a }}$ etapa foram selecionados alguns exercícios para o aquecimento e preparação dos participantes, constituídos por um trabalho de conscientização corporal, de integração grupal, de autoconscientização e autopercepção, percepção de si e do outro, seguidos de diversos exercícios específicos de integração grupal, com o apoio de jogos dramáticos, técnicas de improvisação teatral e dinâmica grupal; $3^{\text {a }}$ etapa - vivência e dramatização do tema escolhido; $4^{\text {a }}$ etapa - discussão e depoimentos. Para ajudá-los nessa conversa final, foram lançadas as seguintes questões: o que vocês sentiram da atividade de hoje? Como foi participar da encenação? Como o grupo pode ajudar na reabilitação? A discussão e depoimentos foram gravados. Durante os encontros, foram feitos registros fotográficos e anotações em diário de campo, por duas colaboradoras terapeutas ocupacionais, treinadas para esse fim.

No total, foram realizados quatro encontros grupais, distribuídos no período de dezembro de 2009 a janeiro de 2010. Para a concretização desse grupo, a equipe 
multiprofissional do serviço (Caps I, interior de São Paulo) responsabilizou-se pela seleção dos participantes, tendo-se convidado doze sujeitos, em um primeiro momento. Foi, então, proposto um encontro prévio com o fim de conhecêlos e esclarecê-los sobre o objetivo da pesquisa e a atividade a ser utilizada em grupo; porém, apenas seis mostraram interesse e, desses seis, dois desistiram no início, e o grupo permaneceu com quatro participantes, que constituíram o grupo definitivo, sendo um homem e três mulheres, com idade entre 20 e 52 anos, dois solteiros, uma casada e uma viúva, dois em internação semi-intensiva e dois em internação não intensiva, acrescentando-se que nenhum desses sujeitos trabalha. São portadores de transtornos mentais diversos, tais como: transtorno fóbico-ansioso, transtorno delirante orgânico, transtorno esquizoafetivo e transtorno afetivo bipolar. Os familiares foram informados do objetivo, assinando o termo de consentimento livre e esclarecido, assim como os usuários.

O projeto foi submetido ao Comitê de Ética em Pesquisa envolvendo Seres Humanos da Escola de Enfermagem de Ribeirão Preto - Universidade de São Paulo, aprovado sob Protocolo nº $1049 / 2009$, e conta com o financiamento da Fundação de Amparo à Pesquisa do Estado de São Paulo.

\section{Resultados e Discussão}

Frente à questão norteadora, "O que significa para você ser um portador de transtorno mental?", a partir das entrevistas iniciais e da discussão em grupo, foram levantados significados diversos, através dos relatos das próprias situações cotidianas, de forma individual, estendendo-se ao grupal, o que permitiu o destaque para alguns temas. Ao se analisar esses significados, apoiouse nas premissas do Interacionismo Simbólico: 1) o ser humano age com relação às coisas que lhe dão sentido. Essas coisas incluem objetos físicos, seres humanos, instituições, ideias, situações da vida cotidiana etc.; 2) o sentido dessas coisas é derivado da interação social que se estabelece com outras pessoas; 3 ) esses sentidos podem ser manipulados e modificados, a partir de um processo interpretativo, relacionado às coisas com as quais o indivíduo se depara ${ }^{(14)}$. Assim, a adoção do Interacionismo Simbólico como referencial de apoio para a análise dos conteúdos - já que esse se preocupa em compreender os aspectos internos experimentais da conduta humana, a maneira como as pessoas percebem os fatos ou a realidade a sua volta, e como elas agem em relação às suas convicções -, permitiu estabelecer juízo de valor do fenômeno investigado ${ }^{(16)}$.

O teatro improvisado requer intenso relacionamento de grupo, pois é a partir do acordo e da situação em grupo que emerge o material para as encenações ${ }^{(17)}$. Assim, a partir dos dados colhidos, destacaram-se alguns temas comuns entre os participantes, os quais foram encenados, por meio da técnica teatro espontâneo do cotidiano: o portador de transtorno mental e a família; o preconceito, o medo de ser e assumir ser portador de transtorno mental; a causa de ser um portador de transtorno mental.

\section{O portador de transtorno mental e a família}

Os relatos se referenciavam ao modo como a família agia em relação ao transtorno mental, e os cuidados que dela provinham, em relação ao portador. Algumas das falas traziam o discurso de que a família tinha o papel de apoio, porém, outras agiam ao contrário. ... sair sozinho assim, essas coisas, viajá, porque minha mãe tem muito medo de eu sair porque e acontece coisas comigo, desmaiar (...) só tenho o apoio da minha mãe só, de mais ninguém (sujeito 1). Eles até tentam me ajudar, mas quem tá me ajudando mais nisso é meu cunhado mesmo (sujeito 2). Ai às vezes meus filho, eles, só um, às vezes ele me trata assim mais como doente né, minha filha não, ela cuidou de mim, não vou dizer que ela não cuidou, mas ela não se preocupa saber se eu tomo remédio, muito difícil, vagamente ela pergunta mãe tá tomando remédio? (sujeito 3).

A família é o alicerce principal para o desenvolvimento humano e social, e possui forte influência na forma como as pessoas interpretam o mundo ${ }^{(18)}$. A doença mental, dita como grave e de longa duração, provoca uma série de respostas nas pessoas, inclusive entre aquelas do convívio familiar ${ }^{(19)}$. Sabe-se que a família representa fator importantíssimo no cuidado da pessoa com transtorno mental, principalmente daquelas com transtornos graves e severos, que possuem pouca autonomia e que necessitam de apoio contínuo. No entanto, apesar disso, as políticas públicas de saúde mental não têm dado a devida atenção para essas famílias ${ }^{(20)}$. Dessa forma, podem apresentar dificuldades em promover a independência e autonomia do portador de transtorno mental ${ }^{(21)}$.

O preconceito, o medo de ser e assumir ser um portador de transtorno mental

Em muitos momentos, aparece a concepção de que ser portador de transtorno mental não é ser normal; portanto, sofrem, em sua maioria, de preconceitos próprios e alheios acerca do que são e do que não são capazes de fazer. É, umas pessoas criticam, acha que é louco, só quem frequentam aqui é louco né e outros não, outros tratam eu como normal mesmo, mas a maioria (...) Ah eu me sinto normal, eu respondo lá não é, vocês precisam ver que lá não é louco que frequenta lá, quando tem louco eles manda pras clínica, lá é tudo gente normal, muito já parou de tomar de remédio, outros tão frequentando, evoluindo, ficando bom com o tratamento (sujeito 3). Normal é escrever, é fazer conta, isso que é normal pra mim, e eu num faço isso hoje em dia (...) num escrevo direito, num faço conta direito (sujeito 4). Eu acho que sou normal como antes, mas eu num sou, eu sei que mudou a minha vida (sujeito 1).

No modo asilar, o portador de transtorno mental era visto como doente, os sujeitos eram fragmentados e encadeados como mercadorias de produção. Essa concepção foi extremamente apoiada nos moldes de uma prática excludente e alienante, e, apesar de todo o processo da reforma psiquiátrica, ela ainda repercute em alguns cenários $^{(22)}$. As pessoas com transtorno mental ainda são punidas através da segregação e do estigma que sofrem, passam por exclusão social devido ao afastamento das pessoas $^{(20)}$. Pensar em normal e patológico depende do ponto de vista que a sociedade tem a esse respeito. E nesse aspecto, ela é sempre influenciada pela cultura. A normalidade revela o poder do diagnóstico, vindo a rotular 
o indivíduo, significando a perda de um emprego, a perda do pátrio poder dos filhos, a internação em um hospital psiquiátrico e ter como identidade o estigma de "louco"(23).

\section{A causa de ser portador de transtorno mental}

Em outros momentos, relatam sobre concepções e causas que atribuem à condição de ser portador de transtorno mental. Sabe-se, atualmente, que a causa do adoecimento mental é multifatorial e que muitas são as atribuições dadas a esse transtorno. Percebem-se, nas falas, as diversas tentativas de explicação para a causa de ser um portador de transtorno mental. Comigo foi assim, eu nasci assim (sujeito 2). Será porque quando eu era pequena eu caí duma árvore, é eu penso porque eu fiz eletro, tudo num deu problema de cabeça, num deu nada (...) mas acho que num foi através disso porque num tenho nada de cabeça (...) o meu foi emocional (sujeito 3). Agora isso ai eu tenho desde o cinco anos, então num tem nada a vê com meu padrasto (...) problema hereditário num tem, isso aí num tenho (sujeito 1). Em um estudo sobre as percepções da doença mental, observouse que o portador de transtorno mental associava essa condição a vários significados: a doença como solidão, a doença como sofrimento, a doença como descrição/ presença de sintomas e a doença como dificuldade ${ }^{(24)}$.

Diante desses significados atribuídos ao transtorno mental, pode-se considerar que a pessoa é vista pelo que ela apresenta. É vista pelos sintomas da doença, que pedem uma classificação, e não como uma pessoa que tem nome, identidade, vida própria; a subjetividade fica muito distante de qualquer consideração ${ }^{(24)}$.

Em relação à etapa preparatória dos exercícios e aquecimentos, os sujeitos puderam vivenciá-los de forma descompromissada e espontânea. Os jogos reproduzem características essenciais da vida, possuem regras e leis, as quais são necessárias para que se realizem, ajudam na desmecanização do corpo e da mente frente à alienação do dia a dia, tornando-se diálogos sensoriais que permitem a criatividade ${ }^{(2)}$. Eu fico assim com dificuldade de expressar sabe, eu sou muito fechado (...) então você tá me ajudando bastante (sujeito 1). Eu acho que no relaxamento pode ajudar nós, eu gostei do relaxamento isso aí pode ajudar a gente bastante (sujeito 4). Através do jogo, a liberdade pessoal é liberada, e a pessoa, como um todo, é física, intelectual e intuitivamente despertada ${ }^{(17)}$.

Observou-se que em alguns momentos a interação tornou-se simbólica, ou seja, quando os atos de cada indivíduo têm significado para o criador e o recebedor da ação ${ }^{(14)}$. O que aconteceu com ela já aconteceu comigo também; isso ai já aconteceu várias vezes num foi uma ou duas (sujeito 1). É, o que ela falou comigo mexeu comigo também porque aconteceu comigo também (sujeito 3). Foi bom, eu gostei, gostei porque a gente vê como que é a imagem do outro (sujeito 4).

Algumas ressignificações foram feitas. Deixa eu ver, mudança, assim muitas coisa que eu pensava antes sabe que eu num era só o único só sabe que tem problema muita gente tem problema (sujeito 1). Acho que melhorou, melhorou que eu tô mais no mundo real agora (sujeito 2). Eu tinha depressão e eu num sabia que eu tinha transtorno mental num sabia ninguém nunca tinha falado (sujeito 3). Então isso, se vai ali, você vê que tem outros problemas e o teu parece que é pequeno e eu gostei disso aí (sujeito 4). O processo terapêutico ocupacional e a realização de atividades apresentam-se como possibilitadores de novos caminhos para o fazer, na relação que se estabelece durante o fazer partilhado, como a relação de ensinar, aprender, construir, inventar, criar. Oferecem espaço para uma experiência individual prazerosa, no qual fatos da vida são vividos de forma diferente ${ }^{(1)}$. Pode-se pensar, ainda, à luz do Interacionismo Simbólico, que cada ato também seja considerado uma nova interação com o mundo, pois a ordem dos fatos sociais e o sentido das ações estão sujeitos sempre a mudanças ${ }^{(16)}$.

\section{Considerações Finais}

Com o intuito de caminhar junto aos princípios da reabilitação psicossocial, faz-se necessário repensar a assistência aos portadores de transtornos mentais, o que sugere novos espaços e formas de lidar com esse tipo de doença. Essas novas formas e práticas da assistência se expressam pelo entendimento do indivíduo como cocriador desse processo de renovação. A partir da concepção inicial de que carrega historicamente o peso da opressão e do sofrimento, ao se sentir como cocriador, há a oportunidade do exercício da voz e do direito à cidadania. É nesse contexto que se insere o teatro espontâneo do cotidiano, como instrumento terapêutico ocupacional, que sugere novos espaços em saúde, oferecendo o exercício do fazer criativo em busca de soluções para as problemáticas encenadas do cotidiano. A partir dessa experiência, por meio da interação simbólica, foi possível transformar antigos significados sobre portadores de transtorno mental - antes remetentes sempre ao medo, ao preconceito, à causa, à família -, em ideias positivas.

Após a efetivação da Reforma Psiquiátrica, é importante destacar que as terapias tradicionais, incluindo a terapêutica com os psicofármacos, têm verdadeiro potencial para controlar a sintomatologia psiquiátrica de forma eficaz, mas, tal potencial não é o mesmo no que se refere à manutenção desse controle. Assim, as modalidades terapêuticas não tradicionais, que incluem o teatro espontâneo do cotidiano, apresentam-se como um meio para auxiliar nessa manutenção. Ao se propor o teatro espontâneo do cotidiano como instrumento a ser utilizado na assistência à saúde mental, criou-se espaço para melhor compreensão dos significados do que é ser portador de transtorno mental, possibilitando contribuir para a reabilitação psicossocial dessa categoria de pacientes.

\section{Referências}

1. Benetton MJ. Trilhas associativas: ampliando recursos na clínica da terapia ocupacional. São Paulo: Centro de Estudos de Terapia Ocupacional; 1999. 141 p.

2. De Carlo M, Bertalotti C. Caminhos da Terapia Ocupacional. In: De Carlo M, Bertalotti C, organizadoras. Terapia Ocupacional no Brasil: fundamentos e perspectivas. São Paulo: Plexus; 2001. p. 19-40.

3. Millani HFB, Valente MLLC. O caminho da loucura e a transformação da assistência aos portadores de sofrimento mental. SMAD, Rev. 
Eletrônica Saúde Mental Álcool Drog. (Ed. port.) [periódico na Internet]. 2008;4(2). [19 telas]. [acesso 23 ago 2010]. Disponível em: http://www2.eerp.usp. $\mathrm{br} / \mathrm{resmad} /$ verArtigo_port.php?idioma=portugues\&a no $=2008 \&$ volume $=4 \&$ numero $=2 \& i d=130$.

4. Amarante P. Loucos pela Vida: A trajetória da Reforma Psiquiátrica no Brasil. 2 ed. Rio de Janeiro: Fiocruz; 2001. $132 \mathrm{p}$.

5. Mângia EF. Contribuições da abordagem canadense "prática de Terapia Ocupacional centrada no cliente" e dos autores da desinstitucionalização italiana para a Terapia Ocupacional em saúde mental. Rev Ter Ocup Univ São Paulo. 2002;13(3):127-34.

6. Nicácio F, Campos GWS. A complexidade da atenção às situações de crise - contribuições da desinstitucionalização para a invenção de práticas inovadoras em saúde mental. Rev Ter Ocup Univ São Paulo. maio-ago 2004;15(2):71-81.

7. Pitta A. O que é reabilitação psicossocial no Brasil, hoje? In: Pitta A, organizadora. Reabilitação Psicossocial no Brasil. 2 aed. São Paulo: Hucitec; 2001. p. 19-26.

8. Liberman F. Trabalho corporal, música, teatro e dança em Terapia Ocupacional: clínica e formação. Cad Centro Universitário São Camilo. jul-set 2002;8(3):39-43.

9. Castro ED, Lima EMFA, Brunello MIB. Atividades Humanas e Terapia Ocupacional. In: De Carlo M, Bertalotti C, organizadores. Terapia Ocupacional no Brasil: fundamentos e perspectivas. São Paulo: Plexus; 2001. p. 41-59.

10. Castro ED, Silva RJG. Processos Criativos e Terapia Ocupacional. Rev Ter Ocup Univ São Paulo. 1990;1(2):71-5. 11. Mendonça MP. O sentido da vida no envelhecer: o teatro espontâneo do cotidiano como um recurso em terapia ocupacional. [Tese de Doutorado em Saúde Pública]. São Paulo: Faculdade de Saúde Pública da Universidade de São Paulo; 2003. 122 p.

12. Covas CA, Torricelli ACS. Teatro espontâneo do cotidiano: uma proposta de intervenção em terapia ocupacional e fonoaudiologia junto a pacientes hipertensos e diabéticos da terceira idade. Rev Centro Univ Claretiano Batatais. jan-dez 2003;(3):145-58.

13. Saraceno B. Libertando Identidades: da reabilitação psicossocial à cidadania possível. Belo Horizonte: Te Corá; $1999.176 \mathrm{p}$.

14. Blumer H. Symbolic interacionism: perspective e method. Berkeley: University of California; 1969. 208 p. 15. Minayo MCS. O desafio do conhecimento: pesquisa qualitativa em saúde. 8 ed. São Paulo: Hucitec; 2004. 269 p.
16. Santos RS. Interacionismo Simbólico: uma abordagem teórica de análise na saúde. Rev Enferm Bras. jul-ago 2008;7(4):233-7.

17. Spolin V. Improvisação para o teatro. São Paulo: Perspectiva; 2005. 349 p.

18. Schrank G, Kantorski LP. Ações de Saúde Mental desenvolvidas nos centros de atenção psicossocial voltadas à família do portador de transtorno psíquico. Rev Fam Saúde Desenvol. set-dez 2003;5(3):203-12.

19. Nagaoka AP. Usuários de um Centro de Atenção Psicossocial e suas vivências com a doença mental. [Dissertação de Mestrado em Enfermagem Psiquiátrica]. Ribeirão Preto: Escola de Enfermagem de Ribeirão Preto da Universidade de São Paulo; 2009. 80 p.

20. Ribeiro MBS, Martins STF, Oliveira LR. Familiares de usuários vivenciando a transformação do modelo assistencial psiquiátrico. Estudos Psicol. mai-ago 2009;14(2):133-40.

21. Milliken PJ, Northcott HC. Redefining parental identity: caregiving and schizophrenia. Qual Health Rev. 2003;13(1):100-13.

22. Costa-Rosa A. O Modo psicossocial: um paradigma das práticas substitutivas ao modo asilar. In: Amarante P, organizador. Ensaios: subjetividade, saúde mental, sociedade. Rio de Janeiro: Fiocruz; 2000. p. 141-68.

23. Bock AMB, Furtado O, Teixeira MLT. Psicologias: uma introdução ao estudo de psicologia. São Paulo: Saraiva; 2005. $492 \mathrm{p}$.

24. Gentile C, Pereira MAO. A doença mental: visão de pacientes psicóticos. Cogitare Enferm. mai-ago 2005;10(2):17-23.

25. Boal A. Teatro do Oprimido e outras Poéticas Políticas. $7^{\mathrm{a}}$.ed. Rio de Janeiro: Civilização Brasileira; 2005. 303 p.

\section{Como citar este artigo:}

Assad FB, Pedrão LJ. O significado de ser portador de transtorno mental: contribuições do teatro espontâneo do cotidiano. SMAD, Rev. Eletrônica Saúde Mental Álcool Drog. (Ed. port.). maio-ago. 2011 [acesso: em: ];7(2):92-7. Disponível

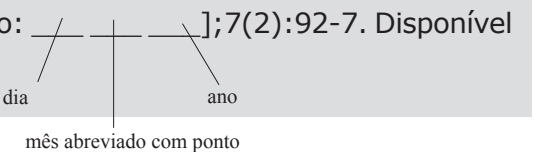
mês abreviado com ponto 